\title{
The challenge of forecasting impacts of flash floods: test of a simplified hydraulic approach and validation based on insurance claim data
}

\author{
Guillaume Le Bihan $^{1}$, Olivier Payrastre ${ }^{1}$, Eric Gaume ${ }^{1}$, David Moncoulon ${ }^{2}$, and Frédéric Pons ${ }^{3}$ \\ ${ }^{1}$ IFSTTAR, GERS, EE, F-44344 Bouguenais, France \\ ${ }^{2}$ CCR, 157 boulevard Haussmann, 75008 Paris, France \\ ${ }^{3}$ Cerema, Direction Méditerranée, 30 rue Albert Einstein, F-13593 Aix-en-Provence, France
}

Correspondence to: Olivier Payrastre (olivier.payrastre@ifsttar.fr)

Received: 16 June 2017 - Discussion started: 26 June 2017

Revised: 5 October 2017 - Accepted: 15 October 2017 - Published: 28 November 2017

\begin{abstract}
Up to now, flash flood monitoring and forecasting systems, based on rainfall radar measurements and distributed rainfall-runoff models, generally aimed at estimating flood magnitudes - typically discharges or return periods - at selected river cross sections. The approach presented here goes one step further by proposing an integrated forecasting chain for the direct assessment of flash flood possible impacts on inhabited areas (number of buildings at risk in the presented case studies). The proposed approach includes, in addition to a distributed rainfall-runoff model, an automatic hydraulic method suited for the computation of flood extent maps on a dense river network and over large territories. The resulting catalogue of flood extent maps is then combined with land use data to build a flood impact curve for each considered river reach, i.e. the number of inundated buildings versus discharge. These curves are finally used to compute estimated impacts based on forecasted discharges. The approach has been extensively tested in the regions of Alès and Draguignan, located in the south of France, where welldocumented major flash floods recently occurred. The article presents two types of validation results. First, the automatically computed flood extent maps and corresponding water levels are tested against rating curves at available river gauging stations as well as against local reference or observed flood extent maps. Second, a rich and comprehensive insurance claim database is used to evaluate the relevance of the estimated impacts for some recent major floods.
\end{abstract}

\section{Introduction}

Hydro-meteorological forecasts are essential for efficient real-time flood management, especially when the situation is evolving rapidly. Forecasts provide crucial information to emergency managers for the anticipation and appraisal of the forthcoming floods that may affect areas at risk. In the particular case of flash floods, often affecting simultaneously a large number of small ungauged streams, suitable forecasting systems are still currently under development around the world. The first approaches developed, namely the flash flood guidance, were based on a preliminary analysis of rainfall volumes generating bankfull flow, for several durations and initial soil moisture conditions (Georgakakos, 2006; Norbiato et al., 2008). More recent approaches aimed to directly forecast peak discharges at ungauged locations based on highly distributed hydrological models and radar based quantitative precipitation estimates (QPEs) or nowcasts (Cole and Moore, 2009; Rozalis et al., 2010; Wang et al., 2011; Javelle et al., 2014; Gourley et al., 2014, 2017; Naulin et al., 2013; Versini et al., 2014). Such models provide indications of possible flood magnitudes, but are still rarely designed to directly evaluate the possible associated impacts. A large number of simultaneous alarms may be generated in the case of a significant rainfall event by such highly distributed flash flood forecasting systems. And it is now recognised that end users, such as emergency managers, who have little time for situation analysis and decision making during flash floods, crucially need rapid assessment of the possible field consequences and damage severity 
(Schroeder et al., 2016; Cole et al., 2016). Moreover, a direct forecast of possible field consequences opens the possibility for assessing the performance of flash flood forecasting systems in ungauged areas, based on reported consequences, as a surrogate for measured flood discharges (Versini et al., 2010a; Naulin et al., 2013; Javelle et al., 2014; Moncoulon et al., 2014; Saint-Martin et al., 2016; Le Bihan et al., 2016). In the near future, real-time assimilation of proxy data for flood magnitude such as information contained in reports of rescue services or social networks can be envisaged. This article presents a proposal of such an integrated flash flood impact forecasting chain and illustrates its validation against insurance claims. If successful, such an approach may be of great help for both emergency managers to better appraise the expected flash flood impacts, and for hydrologists to improve their modelling approaches in ungauged situations.

Translating discharges into local possible impacts requires an estimation of the corresponding flood extent, as well as the knowledge of the level of exposure (location) of the considered assets and possibly of the vulnerability of these assets. This information may be difficult to assess and incorporate at the large scale at which flash flood forecasting systems are implemented to monitor a large number of small streams. Large-scale flood mapping approaches based on digital terrain models (DTMs) were recently proposed and tested (Yamazaki et al., 2011; Pappenberger et al., 2012; Sampson et al., 2015). These works may offer an interesting way for automatic treatment of DTM and flood mapping. But they were not initially designed for the simulation of a large range of flood magnitudes and were generally applied at relatively large spatial resolutions: computation square grids from $100 \mathrm{~m}$ up to $1 \mathrm{~km}$. Such resolutions are not suited to the representation of floodplains of small streams. On the other hand, detailed flood inundation mapping approaches are available at higher resolutions (Bradbrook et al., 2005; Sanders, 2007; Nguyen et al., 2015), but require large computational resources which limit the implementation possibility at a large scale. In both cases, most of the proposed mapping approaches would not be compatible with application in real time.

The approach proposed hereafter combines applicability at a large scale (computational efficiency), the possibility to be integrated in a real-time forecasting chain, and high spatial resolution for an appropriate representation of floodplains of small ungauged streams. It is proposed to compute automatically (i.e. without manual corrections) a series of flood extent maps for each river reach (a river reach being defined as the portion of river located between two confluences), covering a large spectrum of discharge values (i.e. discharge return period values). A DTM treatment method is proposed for the extraction of river cross sections, which are used in onedimensional (1-D) steady-state hydraulic numerical models for the computation of water stages and flood extent maps. Land use databases are then analysed to compute the number of buildings in the estimated flooded areas for each discharge value and each river reach. Based on this preliminary analysis, a relationship between the discharge and the number of affected buildings is adjusted at the river reach scale and is then used as impact model of an integrated rainfall-runoffimpact simulation chain.

Even if the proposed procedure may appear relatively straightforward, the main challenge lies in its automatic application and validation over extended territories on a dense stream network - typically streams with upstream watershed areas larger than $5 \mathrm{~km}^{2}$. The validation is an essential step which should reveal if such a forecasting chain is able to provide reasonably accurate results, despite the necessary simplifications of such large-scale applications (standard roughness coefficient values, 1-D steady-state hydraulic models, missing bathymetric data, etc.), and sources of uncertainty (DTM accuracy, unknown vulnerabilities, etc.).

This article presents the proposed method and its application on two well-documented test case studies. Two types of evaluations are conducted. First, the automatically computed flood maps and corresponding water levels are tested against the rating curves at river gauging stations as well as against local reference or observed flood maps. Second, a rich and comprehensive insurance claim database provided by the largest French reinsurance company (Caisse Centrale de Réassurance) is used to evaluate the relevance of the estimated impacts (number of possibly inundated buildings) for some recent major floods. The article is organised as follows: the first section presents the methodology developed for both the implementation of the impact model, including the computation of a catalogue of flood extent maps, and for the implementation of the rainfall-runoff-impact simulation chain; Sect. 3 presents the two application case studies and the data sets used for the validation; Sect. 4 examines and discusses the obtained results.

\section{The proposed rainfall-runoff-impact simulation chain}

\subsection{Simplified automatic implementation of 1-D steady-state hydraulic models}

The Cartino method (Pons et al., 2014), has recently been proposed to automatically build the input files and run onedimensional (1-D) hydraulic models based on data extracted from high-resolution DTMs. This method has been used and adapted herein to derive catalogues of flood extent maps for a wide range of discharge values. The software proceeds in three steps (Fig. 1). First, the locations of the cross sections are selected (Fig. 1a) and their shapes extracted from the DTM (Fig. 1b). Second, the corresponding input files are built and the selected 1-D hydraulic model is run to compute longitudinal water level profiles corresponding to each selected discharge value (Fig. 1b): the Mascaret 1-D model (Goutal et al., 2012) has been used in the present case study. 


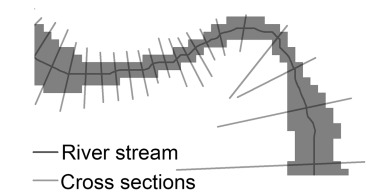

(a) Approximated flood extent
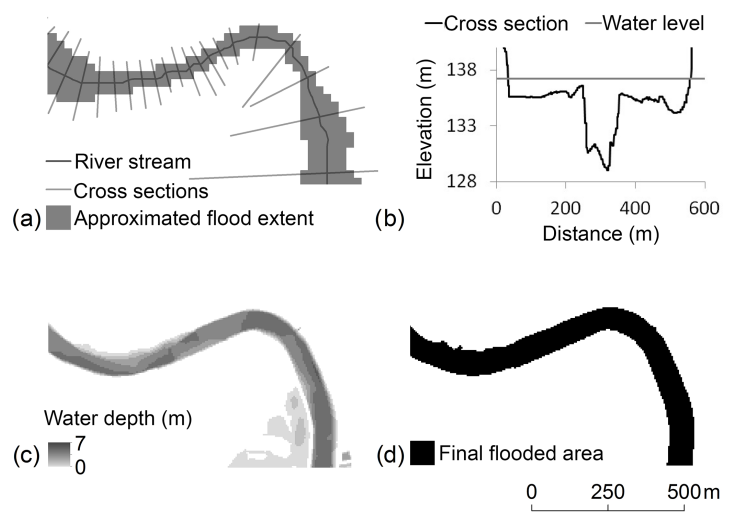

Figure 1. Overall principle of the computation of flood maps based on CartinoPC software: (a) input information (position of river streams and approximated extent of flooded area) and position of cross sections, (b) example of one cross section including the computed water level (1-D hydraulic model), (c) map of flooded areas and water depths obtained after post-treatment, (d) final map of flooded areas after removal of disconnected areas.

Third, the estimated water levels are interpolated between successive cross sections and compared to the DTM elevations to compute the flood extent and water depth maps (Fig. 1c).

The first two steps are run in an iterative way to adjust the width of the cross sections and their inter-distances for each considered discharge value. The cross sections should be wide enough to contain the simulated flow and successive cross sections should not overlap. The procedure is initiated based on a first estimation of the possible extent of the flooded area (provided as input as well as the position of the river bed; see Fig. 1a), which is used to define the initial width of each section. The distances between profiles are then defined as a proportion of each cross-section width (proportion defined as input parameter). After each run, it is checked if the computed water level does not exceed the altitude of the borders of the cross section. If it is the case, the cross section is enlarged in a proportion also defined as input parameter. Distances between profiles are adapted consequently. Note that the final set of cross-sectional profiles and their locations vary between the runs and depend in particular on the considered discharge value.

To ensure automatic computation, important simplifications are introduced in the structure of the hydraulic model: cross-section shapes are estimated based on a simple extraction from the available DTM, without additional information on topography or bathymetry; specific sections such as weirs or bridges are not represented; a unique roughness coefficient is used for all stream reaches ( $n=0.05$ hereafter); no distinction is made between river bed and floodplain. Of course all these assumptions, even if necessary for the sake of simplicity, may have an impact on the accuracy of the results. This point will be evaluated and discussed in the next sections.
An automatic verification is performed after each hydraulic computation to eliminate the main errors in the shapes of cross sections, mainly associated with the limits of DTM information used as input: bridges still appearing in the DTM, remaining noise due to dense vegetation. This verification is based on the comparison between the wetted areas of the successive cross sections: automatic removal of cross sections appearing as inconsistent with the immediate upstream cross section (ratio between successive wetted areas exceeding 3), before running the hydraulic model again.

One crucial aspect for the computation is the delimitation of the active river bed in presence of depressions in the floodplain (perched rivers). In this case, the choice of the input information (default extent of flooded areas and parameter values) highly influences the result and the computation time. For instance, too wide an initial flooded area or too fast an increase in cross-section widths may lead to incorporating depressions that are not connected to the river bed and hence not active for the considered discharge (Figs. $1 \mathrm{~b}$ and c). This may lead to both overestimation of the local extent of the flooded area and to a decrease in the simulated water level, with an impact on the upstream cross sections due to backwater effects. On the other hand, too narrow an initial flooded area and/or too slow increase in the widths of the profiles highly increases the computation time. To cope with these difficulties, the computations are first conducted for the smallest discharge (2-year flood), using a narrow initial extent of flooded area as input of the Cartino method. The width of the cross sections are then progressively increased to detect as accurately as possible the limits of the river bed. If necessary, the remaining flooded areas disconnected from the river bed are finally removed from the final result (Fig. 1d). The computed flooded area is then used as initial cross-section extent for the next computation (next larger discharge value; see Sect. 2.2), and so on.

\subsection{Definition of the impact model based on a catalogue of flood extent maps}

The hydraulic computations are conducted for each river reach of the considered stream network, and for a range of discharge values corresponding to return periods of $2,5,10$, $20,30,50,100,300,500$, and 1000 years. The discharge quantiles are estimated based on the French SHYREG flood frequency database (Aubert et al., 2014). Nevertheless, the accuracy of this information on flow frequency is not crucial for the implementation of the impact model; it just enables the derivation of flood maps for defined discharge values of relatively homogeneous magnitude for all the considered river reaches.

All the computations are made in steady-state regime to simplify the procedure and facilitate its fast application at a large scale. The underlying assumption is that the extent of flooded areas is mainly influenced by the peak discharges, rather than the flow volumes. This assumption is consistent 
(a)

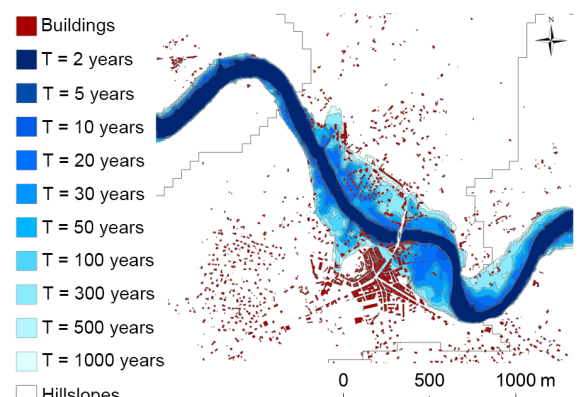

(b)

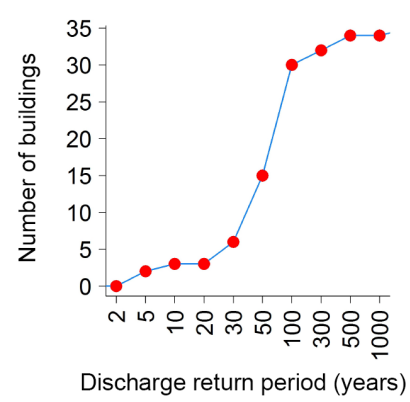

Figure 2. Illustration of the implementation of the impact model on one river reach: (a) catalogue of flooded areas, (b) interpolated dischargeimpact relationship.

with the application domain of the method (flash floods occurring in small upstream watersheds). The discharge is assumed to be homogeneous on each river reach (no lateral flow introduced) as the length of the considered river reaches is limited ( $2 \mathrm{~km}$ in average; see Sect. 3$)$. The roughness coefficient is fixed to $n=0.05$ according to the conclusions of Lumbroso and Gaume (2012) about the relevant range of roughness values in the case of flash floods. The downstream limit condition for each reach is the water level computed for the downstream river reach for the discharge of the same return period. For the last downstream river reach, the boundary condition corresponds to the normal depth for a uniform flow regime. Finally, a post-treatment procedure is applied to ensure better overall consistency of the catalogue of flood extent maps: each map is corrected to systematically include the flood extents computed for the lower discharge values.

Based on this catalogue, an impact model is derived for each river reach. The hillslope limits of the rainfall-runoff model are used to delineate the river reaches and the corresponding flooded areas (Fig. 2a). The assets present in the 10 estimated flooded areas are counted. The number of buildings may be used as an indicator of human asset exposure. More precisely, the number of private houses with a single and georeferenced insurance policy in the available insurance database has been considered herein to enable comparisons with the reported number of insurance claims (Sect. 3.6). The values computed for the 10 flood extent maps for each river reach are then linearly interpolated to build a continuous relationship between discharge and number of flooded houses, i.e. number of impacted insurance policies (Fig. 2b).

\subsection{Main limits of the impact model obtained}

Despite all of the aforementioned precautions, some sources of errors affecting the quality of results remain. These errors are mainly related to the simplification of the procedure necessary for fast and automatic implementation of hydraulic computations over a large river network. These errors are mainly due to
- errors in the retrieval of the shapes of the river cross sections due to the automatic extraction and to the limits of topographic information used (DTM);

- absence of representation of friction losses due to bridges and other hydraulic singularities;

- choice of a fixed Manning roughness coefficient, equal to 0.05 ,

- steady-state regime computations;

- remaining difficulties to determine the active river cross section in cases of perched river bed despite the previously described precautions.

For these reasons, the information obtained should not be considered as a highly accurate estimation of flooded areas and related impacts. It should nevertheless give an order of magnitude of the level of flooding and enable some comparisons of impacts at a regional scale.

\subsection{The rainfall-runoff-impact simulation chain}

The impact model is finally incorporated in a full simulation chain combining radar-based quantitative precipitation estimates (QPEs; see Sect. 3) as input, and a distributed rainfall-runoff model for the simulation of discharges over the stream network. Quantitative precipitation forecasts or nowcasts may also be used as input of the chain to increase anticipation lead times. However, QPEs have been considered herein to focus the analysis on the accuracy of the proposed rainfall-runoff-impact simulation chain.

The CINECAR hydrological model (Gaume et al., 2004; Naulin et al., 2013; Versini et al., 2010b) was selected to build the simulation chain. CINECAR is a distributed rainfall-runoff model based on a representation of the catchment as a ramified series of stream reaches, to which both left and right-hand hillslopes are connected. The spatial resolution of the model (areas of hillslopes and associated length of river reaches) can easily be adapted and has been defined herein to match the resolution of the impact model. This 
means that the river reaches considered are identical in the rainfall-runoff model and in the impact model: they correspond to the same stream network, defined here from an elementary catchment surface of $5 \mathrm{~km}^{2}$.

CINECAR only simulates the rapid component of the runoff and is suited for modelling the rising limb and peak phases of significant flash floods. The Soil Conservation Service-curve number model (SCS-CN) is used to compute runoff rates and the corresponding effective rainfall at each computation time step (USDA, 1986). A temporal resolution of $15 \mathrm{~min}$ has been used here for the computations. The effective rainfall is then propagated onto both the hillslopes and the river network using either the kinematic wave model (Borah et al., 1980), or the Hayami solution for diffusive wave model (Moussa, 1996) to represent the flood wave attenuation in river reaches with slopes less than $0.6 \%$.

Since CINECAR was developed for the purpose of forecasting flood hydrographs in ungauged catchments, it includes a limited number of calibration parameters. For sake of simplicity, the hillslopes are represented by schematic rectangles of the same area as the actual hillslopes, and the river reaches are assumed to have a rectangular cross section. The width of the cross section is the main parameter controlling the transfer function and is estimated based on the Strahler order of river reaches and the discharge return period (Naulin et al., 2013). The curve number $(\mathrm{CN})$ value is the second key parameter which controls the temporal evolution of runoff rates. The USDA method is used for the estimation of the CN (USDA, 1986), depending on the bedrock type, land use, and 5-day antecedent rainfall for initialisation. This model was applied in 2013 to the entire Cévennes Region (Sect. 3), and was validated with respect to measured data (Naulin et al., 2013). It provided satisfactory results for large flood events, similar to the ones obtained with locally calibrated standard conceptual rainfall-runoff models, with an average Nash criterion computed for single flood events equal to 0.49 .

The same model version has been used herein without any further adjustments for the Argens watershed (second case study), whose characteristics are relatively similar to the watersheds of the Cévennes area. The performances of the model on this new application case study could be verified according to stream gauge and peak discharge data available for the June 2010 event.

The discharge values computed with the CINECAR model are finally converted into estimated impacts according to the continuous discharge-impact relationships defined for each river reach (Sect. 2.2 and Fig. 2b).

\section{Presentation of the two case studies}

\subsection{The region of Alès in the Cévennes area, south-eastern France, and the September 2002 flood}

The region of Alès is located in the core of the Cévennes region, well known to be prone to frequent and intense flash floods (Gaume et al., 2009). Moreover, it has been identified during the implementation of the European Union (EU) Floods Directive as one of the areas most exposed to flood risk in France (areas with potential significant flood risk APSFR - selected for the implementation of risk management plans). The region is presented in Fig. 3, indicating the exact limits of the APSFR of Alès. Its vulnerability to floods is mainly related to the presence of the town of Alès, but also to other highly vulnerable smaller towns such as Anduze (Fig. 3).

This territory is part of three main watersheds: the Gardon d'Anduze, the Gardon d'Alès, and the Cèze rivers. These rivers have their upstream course in the Cévennes relief, and reach in their downstream part a plateau area with limited slopes. The APSFR of Alès is located in the transition zone between the mountainous and plateau areas. Therefore, this case study includes a large variety of river bed configurations including steep and narrow $\mathrm{V}$-shaped valleys as well as flat and wide floodplains. Some statistics about the river bed characteristics are provided in Table 1.

The region was hit on September 2002 by a catastrophic flash-flood event (Delrieu et al., 2005). A maximum rainfall accumulation of $680 \mathrm{~mm}$ in $24 \mathrm{~h}$ was recorded in the town of Anduze, which is among the highest daily records in the region (estimated return period widely exceeding 100 years). The estimated peak discharges reached 900 (800$1000) \mathrm{m}^{3} \mathrm{~s}^{-1}$ at Mialet and $3500(3000-4000) \mathrm{m}^{3} \mathrm{~s}^{-1}$ at Anduze on the Gardon d'Anduze river, and 2500 (21002900) $\mathrm{m}^{3} \mathrm{~s}^{-1}$ at Alès on the Gardon d'Alès river. Twentythree casualties and EUR 1.2 billion in damages were reported. This event induced a large number of insurance claims. It has therefore been selected here for the evaluation of the impact simulation chain.

The area selected for the study corresponds to the exact limits of the APSFR of Alès (area of about $1000 \mathrm{~km}^{2}$ ). It includes $400 \mathrm{~km}$ of river streams having at least a $5 \mathrm{~km}^{2}$ upstream catchment area. The stream network has been divided into 192 river reaches, among which only 70 reaches $(132 \mathrm{~km})$ are covered by the current operational flood forecasting service (forecasts published on the Vigicrues website; see main river network in Fig. 3c).

\subsection{The region of Draguignan in the Argens watershed, south-eastern France, and the June 2010 flood}

The Argens river watershed $\left(2700 \mathrm{~km}^{2}\right)$ is located in the eastern part of the French Mediterranean region. It has been hit 


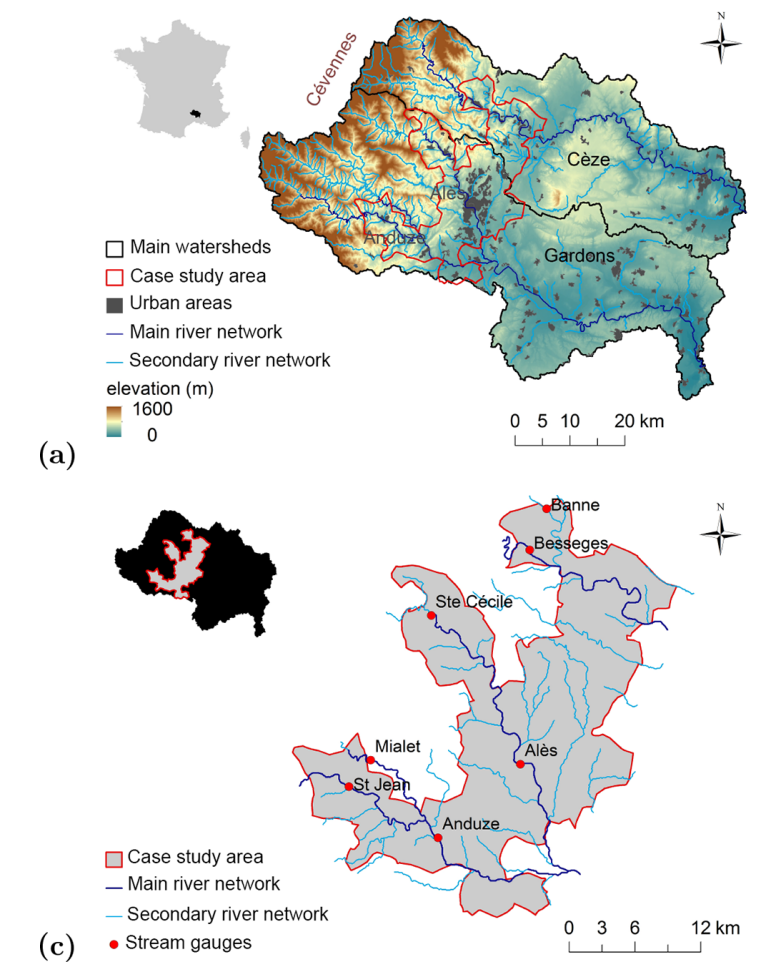

(b)
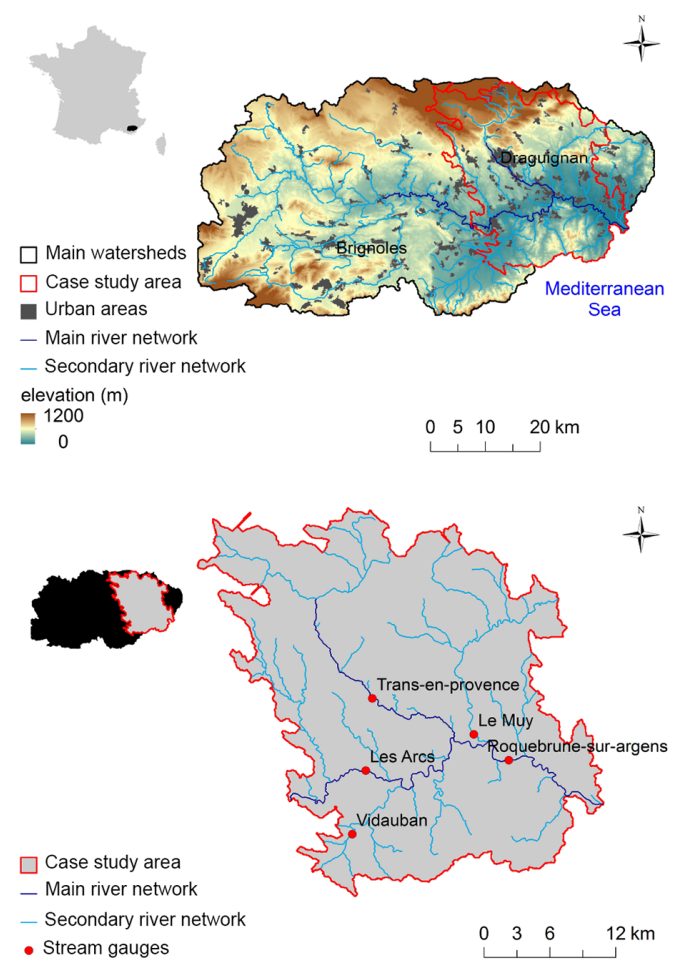

Figure 3. Location of the case studies: (a) APSFR of Alès territory in the Gardon and Cèze watersheds, (b) region of Draguignan in the Argens watershed, and river networks considered in the impact models $\left(5 \mathrm{~km}^{2}\right.$ upstream catchment surface): (c) APSFR of Alès, and (d) region of Draguignan.

Table 1. Characteristics of the river networks considered in the two case studies (extracted from SYRAH database).

\begin{tabular}{|c|c|c|c|c|}
\hline \multirow[t]{2}{*}{ Case study } & & $\begin{array}{r}\text { Bed slope } \\
\text { (percent) }\end{array}$ & $\begin{array}{r}\text { River bed width } \\
(\mathrm{m})\end{array}$ & $\begin{array}{r}\text { Floodplain width } \\
(\mathrm{m})\end{array}$ \\
\hline & & avg./min-max & avg./min-max & avg./min-max \\
\hline \multirow[t]{2}{*}{ Alès } & main network & $0.5 / 0.2-1$ & $37 / 16-84$ & $470 / 120-1670$ \\
\hline & secondary network & $3.4 / 0.2-20$ & $7 / 2-34$ & $430 / 60-3130$ \\
\hline \multirow[t]{2}{*}{ Draguignan } & main network & $0.6 / 0.1-1.2$ & $25 / 5.5-41$ & $730 / 130-3200$ \\
\hline & secondary network & $2.1 / 0.05-21$ & $4 / 1-11$ & $380 / 3-4800$ \\
\hline
\end{tabular}

by several severe flash floods in recent years. This watershed was also selected as an APSFR for the implementation of the EU Floods Directive.

Among recent flash floods observed in this region, the June 2010 event is certainly the most catastrophic one. It particularly affected the region of Draguignan located in the eastern part of the Argens watershed (Fig. 3), where the maximum rainfall accumulation exceeded locally $400 \mathrm{~mm}$ in $24 \mathrm{~h}$ (estimated return period exceeding 100 years). The peak discharges were estimated to $440(360-520) \mathrm{m}^{3} \mathrm{~s}^{-1}$ at Trans-en Provence on the Nartuby river (tributary of the Argens river; see Fig. 3), and respectively 1000 (800$1200) \mathrm{m}^{3} \mathrm{~s}^{-1}$ and $2500(2200-2900) \mathrm{m}^{3} \mathrm{~s}^{-1}$ on the Argens river at Les Arcs and Roquebrune-sur-Argens. Twenty-five casualties and EUR 1 billion in estimated damages were reported after this event as well as a large number of insurance claims.

As for the Alès case study, the region of Draguignan presents a varied topography, and consequently a wide variety of river bed configurations, from narrow valleys in the upstream part of the studied watersheds, to wide floodplains in their downstream part. The area includes $345 \mathrm{~km}$ of rivers with at least $5 \mathrm{~km}^{2}$ upstream catchment areas, which were divided into 173 river reaches. Only 42 of these river reaches are covered by the operational flood forecasting service (Fig. 3d). This illustrates the possible added value of the 
proposed integrated flash flood impact simulation chain in France.

\subsection{Available digital terrain models}

The implementation of the impact models is based on commonly available high-resolution DTMs in both case studies. Nevertheless, the characteristics of these DTMs significantly differ:

- The DTM produced in 2007 by the Conseil Départemental du Gard was available in the case of the Alès case study; it has a $20 \mathrm{~m}$ initial resolution and was interpolated at $5 \mathrm{~m}$; its altimetric accuracy was estimated to less than $20 \mathrm{~cm}$ in non-vegetated areas, and less than $1 \mathrm{~m}$ in vegetated areas.

- The $5 \mathrm{~m}$ resolution DTM extracted from the Institut Géographique National (IGN) RGE Alti database was available in the case of the Draguignan region; its altimetric precision ranges from $20 \mathrm{~cm}$ (main rivers covered with lidar data) to $70 \mathrm{~cm}$ (other areas covered with photogrammetry products for instance), and artificial structures such as bridges are removed in this DTM. This second product can be considered as standard DTM data that will be available over the whole French territory by the end of 2017.

It should finally be noted that if the terrain information used herein is now commonly available in France, its accuracy remains limited and may affect the quality of results: DTMs extracted from lidar measurements are currently limited to the main rivers which are not the scope of this study, and would probably lead to results of better quality. The geographic coverage of lidar data is, however, evolving very fast, and these data should become available also for small rivers in the near future.

\subsection{Rainfall and discharge data}

Both regions are equipped with relatively dense stream gauge and rain gauge networks, complemented with weather radars. In the case of the APSFR of Alès, the whole data set was carefully checked in the framework of the Observatoire Hydro-Météorologique Cévennes-Vivarais (OHM-CV) research observatory. It can therefore be considered as exceeding conventional quality standards.

The locations of stream gauges are shown in Fig. 3. Given the limited possibilities to conduct direct flow measurements during intense flash floods, the rating curves are often extrapolated, with consequently a reduced accuracy of estimated discharges for high water levels and large floods.

Radar-based QPEs are available for both case studies, at $1 \mathrm{~km}^{2}$ spatial resolution and $5 \mathrm{~min}$ temporal resolution. They correspond to the operational Meteo France Panthere QPEs in the case of the Draguignan June 2010 event, and to a radar
QPE reanalysis provided by the OHM-CV research observatory in the case of the September 2002 event in the region of Alès (Delrieu et al., 2009).

\subsection{Reference flood maps from previous studies}

Thanks to the recent application of the EU Floods Directive in both considered areas, great effort was put into mapping flooded areas, leading to detailed inundation maps available for three reference events: the 30-year return period flood ("common" event), 300-year return period flood ("medium" event), and 1000-year return period flood ("large" event). These maps were generally obtained based on 1-D hydraulic modelling, carefully implemented by experts in hydraulics. These maps were criticised and validated using all available information, including the observed extents of inundation during past floods such as the September 2002 and June 2010 floods. These maps were used as a reference here for the evaluation of the computed catalogues of flooded areas. Unfortunately these maps were produced on only part of the considered river networks. This limits the validation possibilities. In the case of the Alès case study for instance, the river network covered by reference maps represents $192 \mathrm{~km}$ (out of $400 \mathrm{~km}$ included in the case study) and includes 84 river reaches (out of 192).

\subsection{Insurance claim database}

Over the last 15 years, an insurance claim database has been developed by the Caisse Centrale de Réassurance (CCR) within the framework of its reinsurance contracts with its clients (Moncoulon et al., 2014). This database covers the entire French territory, and the quality of data is considered as acceptable for the period since 1997. It includes information on both nature and location of insurance policies and claims for all events classified as so-called "CATNAT" events. "CATNAT" events are flood events with an estimated return period exceeding 10 years and consequently for which the natural disaster insurance compensation is activated, in accordance with the compensation scheme in force in France since 1982.

The CCR database is certainly the most comprehensive available database on flood field consequences in France. It has nevertheless some limits, and the content and accuracy of the insurance policy and claim data incorporated have evolved over the years. Consequently the data had to be carefully selected to enable an objective comparison with the modelling results:

- With regard to the policies, the database currently includes more than $80 \%$ of the policies of the French insurance market, insurance against natural hazards being mandatory in France. Great effort has also been put into the accurate georeferencing of the policies in recent years: approximatively $70 \%$ of the policies are geocoded at the street number, about $15 \%$ geocoded at 
the street centre, and $14 \%$ geocoded at the town centre. Only the policies accurately located (i.e. georeferenced at the street number or centre) were considered here for incorporation in the impact model. Note that the address of the policy is generally the address of the owner of the asset. It does often, but not always, correspond to the address of the insured asset. Note also that in the case of flats, several policies can be located at the same address, but are generally not all exposed to flooding. Therefore, only insurance policies and claims corresponding to private houses were considered here to ensure a more direct correspondence between houses, policies exposed to flooding, and claims.

- As far as the claims are concerned, their collation in the database is less systematic: between 30 and $50 \%$ of the total number of CATNAT insurance claims for the French market are documented in the database depending on the year. This depends on the comprehensiveness of the data provided by the insurance companies to the CCR. To base the comparison on faithful and robust data, the policies of the insurance companies documenting more than $80 \%$ of their claims in the CCR database were selected here for the validation of the forecasting chain. The claims with a null compensation amount were also removed, since there is no certainty in this case that real damage occurred, or at least the amount of damage did not exceed the insurance excess in these cases.

Finally, only part of the database could be considered for the comparisons, after application of the above-mentioned selection rules: georeferenced policies, private houses, comprehensiveness of the information on claims provided by the insurance companies. A comparison with the IGN BD Topo database (buildings of $<7 \mathrm{~m}$ height corresponding mostly to individual houses) shows that the number of selected policies represents about $20 \%$ of the total number of buildings in the considered floodplains (Table 2). The proportion is higher in the Draguignan 2010 case, a sign of the improved quality of the CCR database over 2002. To enable a direct comparison of the forecasted impacts with the number of reported claims, the impact model (Fig. 2) was finally built based on the selected policies: the forecasted information corresponds in this case to a number of possibly impacted individual houses, for which almost comprehensive claim data are available. As the details of the insurance data of individuals are confidential, the validation was based on claim data aggregated at the river reach scale. Moreover, to ensure a total confidentiality, the analyses and comparisons were only conducted on river reaches with at least 20 recorded policies in the database.

The analysis of the available claim data reveals some additional surprises. First, despite the comprehensiveness of the selected claim data, the ratio between reported claims and policies rarely exceeds $50 \%$ even in areas which are likely to have been flooded (Fig. 4). Some houses with raised basements may be out of water even in the flooded areas, but not at such a high proportion. This ratio is also explained by the remaining proportion of claims not documented in the database (up to $\sim 20 \%$ according to the data selection), by the significant proportion of claims with a null compensation amount, and maybe also by some non-declaration of flood damages to the insurance companies. The large difference between the number of policies and the number of reported claims is a common feature for all floods in the CCR database (Moncoulon et al., 2014). In total, the combination of the limited proportion of selected insurance policies (policy / building ratio) and of the partial documentation of the claims and damages (claim / policy ratio) leads to a relatively low average ratio between the number of buildings and the number of reported claims in the floodplains: 6 to $9 \%$ (Table 2). This explains why, despite the richness of the CCR database, the evaluation of the proposed forecasting chain based on insurance claims, with the ambition to provide results at the stream reach level, had to be limited to extreme flood events with large numbers of reported claims.

The second major surprise is the significant proportion of reported claims located outside the estimated 1000-year flood envelop (over $10 \%$ for the two considered events; see Fig. 4). This is also a general feature observed in the CCR database. Several explanations can be put forward to explain the presence of claims outside the identified flood areas: (i) damages may be induced by small watercourses not represented in the flood model, (ii) they may also be triggered by other local processes (runoff accumulation in low points, sewer saturation, cellar flooding due to groundwater raising, etc.), and (iii) the address of the owners of the insurance policies may not correspond to the location of the affected assets. Information in the database does not allow for differentiation between damages induced by direct stream flooding and other processes. The existence of a significant proportion of claims not directly related to river overflows represented by the model adds to the complexity of the validation exercise. For the purpose of this validation, and considering that the contours of the flooded area are only available for a limited number of the considered river reaches, every claim located in the maximum possible flood envelop (estimated 1000-year flood envelop) for each stream reach has been considered for the computation of the reference number of observed claims per reach. This could lead to overestimating the reference number of claims for reaches with actual limited flooding and will be discussed in the section presenting the results.

Despite all these constraints which limit the information content of the data, this CCR database is still a rich and unique source of information to measure the impacts of flash floods in small rivers. Until now, it has been used to assess economic losses at the event scale (Moncoulon et al., 2014). We tested here whether it could provide a number of private houses affected by the floods for each river reach, to be compared to the outputs of the proposed forecasting chain. 


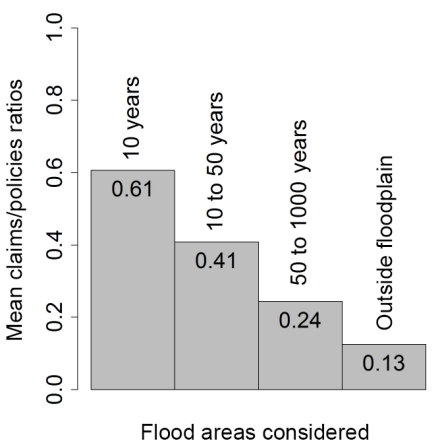

(a)

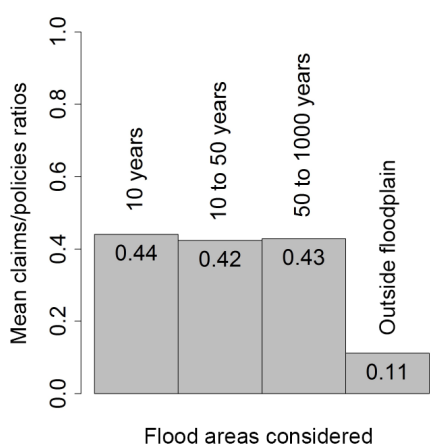

(b)

Figure 4. Spatial distribution of mean claims / policies ratios, inside and outside the floodplains: (a) Alès 2002 event, (b) Draguignan 2010 event.

Table 2. Mean claims / policies and policies / buildings ratios computed inside the 1000-year floodplains for the September 2002 and June 2010 events. The claims and policies are those selected in the CCR database according to the rules described in Sect. 3.6. The buildings considered are those of less than $7 \mathrm{~m}$ height according to the IGN BD Topo database.

\begin{tabular}{lrrr}
\hline & Mean claims / policies ratio & Mean policies / buildings ratio & Global claim / buildings ratio \\
\hline September 2002 & 0.37 & 0.17 & 0.06 \\
\hline June 2010 & 0.43 & 0.21 & 0.09 \\
\hline
\end{tabular}

\section{Results and discussion}

As mentioned in the introduction, the results are presented hereafter in two steps:

- First, an evaluation of the accuracy of the catalogue of flooded areas is presented based on the Alès case study. Two different types of evaluations results are examined: the water levels estimated at stream gauges are compared to existing stage-discharge relationships (rating curves), and the estimated flooded areas are compared to reference areas computed for the purpose of the implementation of the EU Floods Directive.

- Second, the results of the whole rainfall-runoff-impact simulation chain are presented for the both case studies, i.e. the September 2002 and June 2010 floods, and evaluated against real observed flooded areas and insurance claim data.

\subsection{Comparison of water levels at stream gauges locations (Alès case study)}

A first evaluation of the results of hydraulic computations is proposed here based on information available at stream gauges. These gauges indeed offer locally the opportunity to compare the rating curves based on expert know-how with the results of the 10 steady-state hydraulic computations used for the implementation of the impact model. Considering that the distance between cross sections may reach up to $100 \mathrm{~m}$ in the proposed method and that their locations is variable, additional cross sections corresponding to the exact locations of the stream gauges were manually added for the hydraulic computations to enable comparisons.

The results are presented in Fig. 5 for three different stream gauges: Mialet, Banne, and Alès. This figure illustrates contrasted situations, which are detailed hereafter. It has first to be mentioned that only the Mialet and Alès stations are used for flood forecasting purposes: for these two stations, the rating curves have been extrapolated based on local hydraulic models. The Banne station is mainly used for low-flow measurements and its rating curve was extrapolated based on an assumption on the hydraulic control of the gauging section; it is nevertheless an interesting case since the station is located on a small tributary.

The case of the Mialet station (Fig. 5a) appears as an ideal situation, where the shape of the cross section is well retrieved from the DTM and the computed water levels are very close to the existing rating curve. Note that the real measured discharge values are low for the three stream gauges. The comparisons are focussed on the extrapolation range of the rating curve; i.e. the automatically implemented hydraulic model is essentially compared with local expert know-how generally based on a detailed hydraulic computation. The very satisfactory result obtained in Mialet may be explained by the simple shape of the cross section (deep and relatively narrow in this case), the limited presence of vegetation in the river bed that could affect local roughness, and the significant slope (i.e. limited risk of backwater influences). The selected roughness coefficient value of 0.05 , an average value based 
(a)
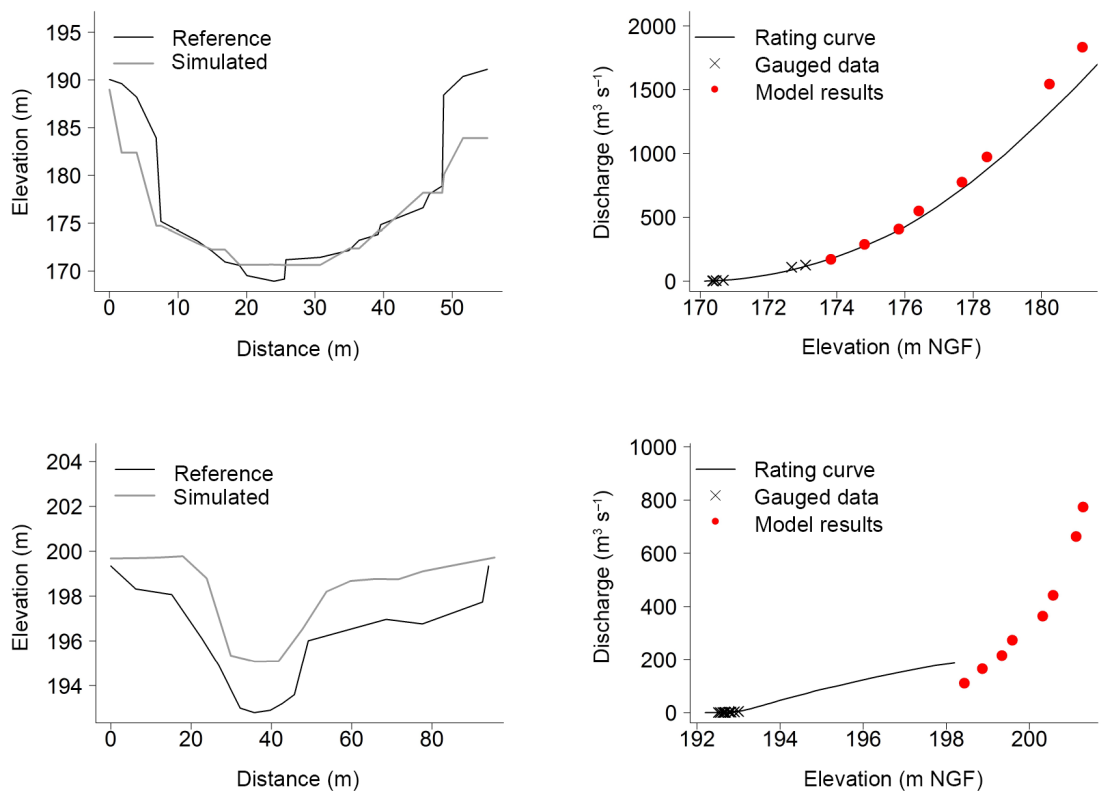

(b)
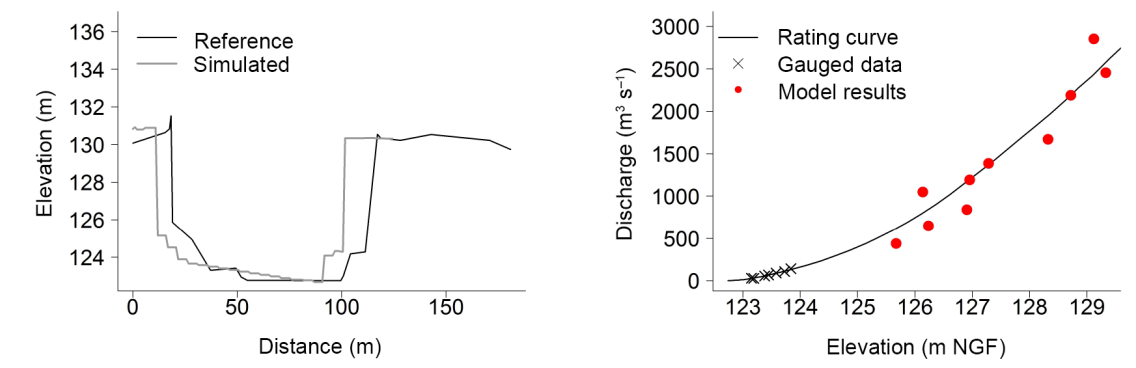

(c)
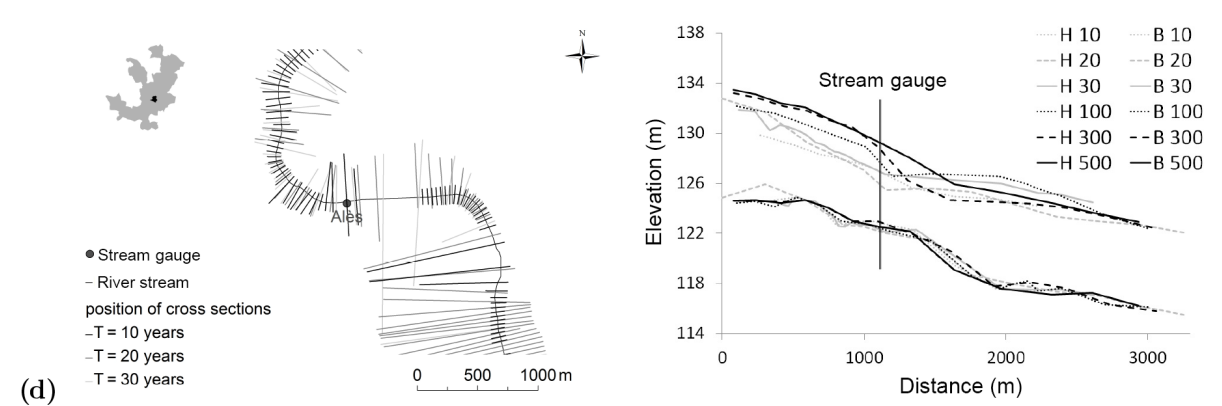

Figure 5. Examples of comparison of cross sections and water levels at three stream gauges: (a) Mialet station, (b) Banne station, (c) Alès station, (d) Alès station: position of cross sections and longitudinal profile of river bed (B) and water levels $(\mathrm{H})$.

on post-event studies (Lumbroso and Gaume, 2012), corresponds well to the locally adjusted one.

The comparison for the Banne station is less satisfactory (Fig. 5b). The two cross sections have similar shapes but do not seem to have the same reference altitude. A difference of about $2 \mathrm{~m}$ exists for an unknown reason. This may nevertheless have little influence on the relative water levels and corresponding computed flooded areas. However, if the computed water levels are reduced by $2 \mathrm{~m}$, the computed discharges still appear much larger than the corresponding discharge estimates based on the local rating curve for the larger stage or discharge values. The slope of the local rating curve appears very low and does not even follow the evolution of cross-sectional areas with the water stages. Such a rating curve shape could result from a local backwater effect and could illustrate the limits of the hydraulic model used, which does not account for such phenomena. In this case, there is nevertheless no hydraulic singularity immediately downstream the gauge that could generate such an effect. The reference extrapolated rating curve is questionable. 


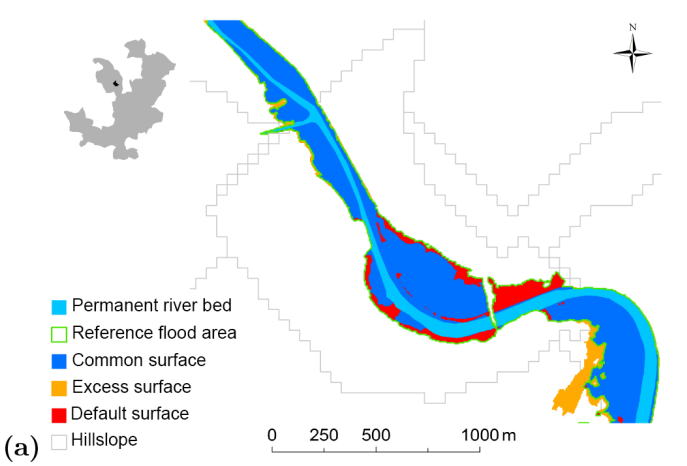

(b)
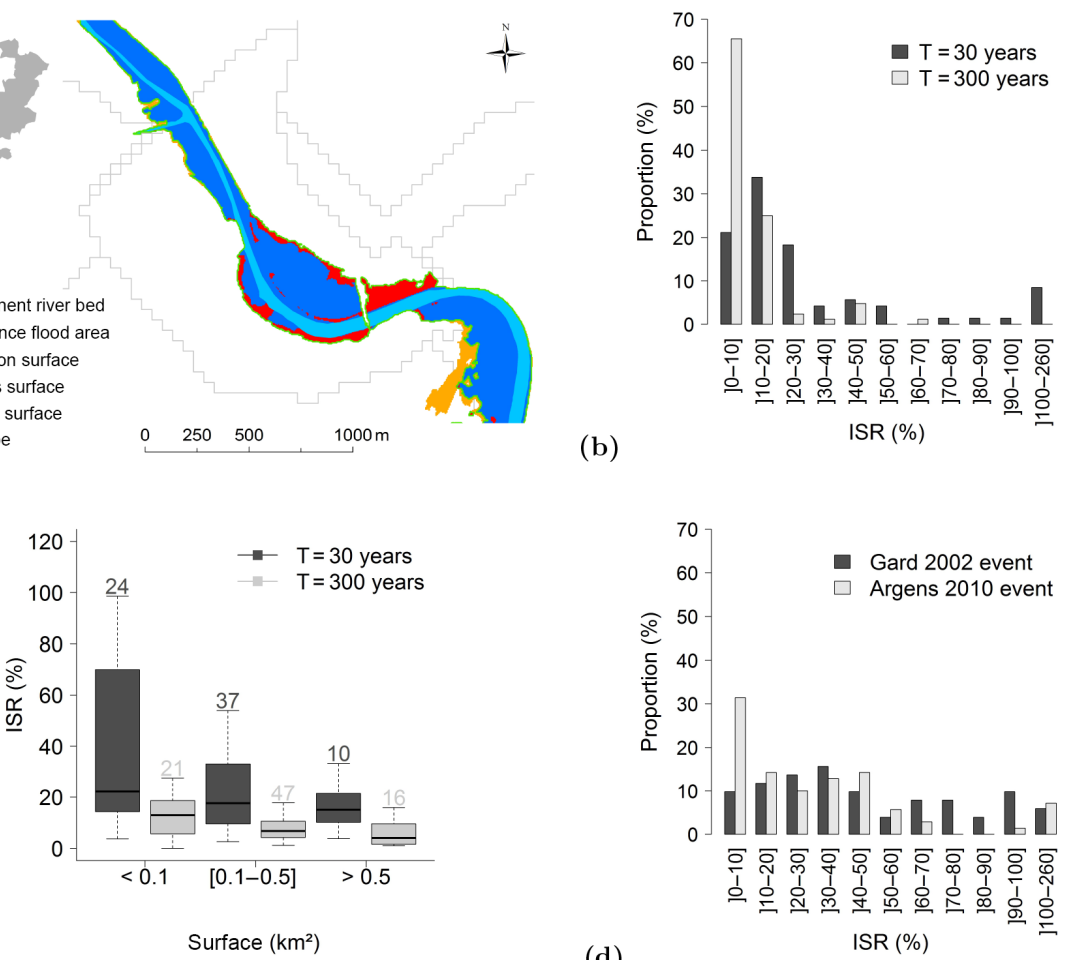

Figure 6. Comparison between estimated and reference flooded areas: (a) definition of common surface $\left(S_{\mathrm{c}}\right)$, excess surface $\left(S_{\mathrm{e}}\right)$, and default surface $\left(S_{\mathrm{d}}\right)$ for the computation of ISRs, (b) distributions of ISR scores for the 30-year and 300-year discharge quantiles on the APSFR of Alès, (c) distributions of ISR scores depending on the extent of the reference flooded area, and (d) distributions of ISR scores for the full simulation chain for the Alès 2002 and Draguignan 2010 events.

The case of the Alès station illustrates other sources of difficulties (Fig. 5c). Again in this case, the topography of the river bed appears well retrieved from the DTM even if a horizontal displacement is noticeable. However, the shape of the computed stage-discharge relationship, even if on average close to the rating curve of the station, appears chaotic and non-monotonous. The stream gauge is located just upstream a large meandering stretch where the valley is perched with a large flood plain on the right bank (Fig. 5d). This flood plain is only inundated during extreme floods. Depending on the run (i.e. on the discharge value), it can be included or excluded from the modelled cross sections located just downstream the gauge and may generate an inundated area not connected to the river bed, finally eliminated in the posttreatment as described previously. However, this artificial inclusion of the flood plain in the cross sections, for some intermediate discharge values, leads to underestimating the computed water level at the gauged cross section due to the backwater propagation (see longitudinal profiles in Fig. 5d). Clearly, the proposed procedure could not eliminate all the problems encountered when modelling perched rivers with 1-D hydraulic models, despite the precautions taken. The use of 2-D hydraulic models could help solve the problems encountered in the future but at the cost of a large increase in computation time. A detailed analysis of the results obtained for the two case studies nevertheless reveals that the number of remaining problematic river reaches is limited. Moreover, these problematic configurations mainly correspond to relatively large rivers $\left(315 \mathrm{~km}^{2}\right.$ of drainage area at the Alès station), which correspond to the limit of the target application domain of the proposed method.

Similar results were obtained for the other available gauging stations. Overall, the results are extremely satisfactory, almost exceeding the initial expectancies. The crosssectional shapes can be correctly retrieved from the existing DTM despite its limits, at least sufficiently accurately for the reconstruction of local stage-discharge relationships. It is important to note that the low-flow water heights are limited in these Mediterranean rivers. This explains why bathymetric data are not crucial to obtain a relevant estimation of the cross-sectional shapes: aerial topographic surveys are often sufficient to get an accurate representation of the river beds in these regions. The selected average roughness coefficient value appears to be suited to the local expert know-how. In the future, checking stage-discharge relationships at gauging stations could help to adjust the values of roughness coefficients in the proposed approach extrapolated to other areas. It is important nevertheless to keep in mind that hydraulic singularities such as bridges, which cannot be characterised through the DTM, may locally largely influence the stage- 

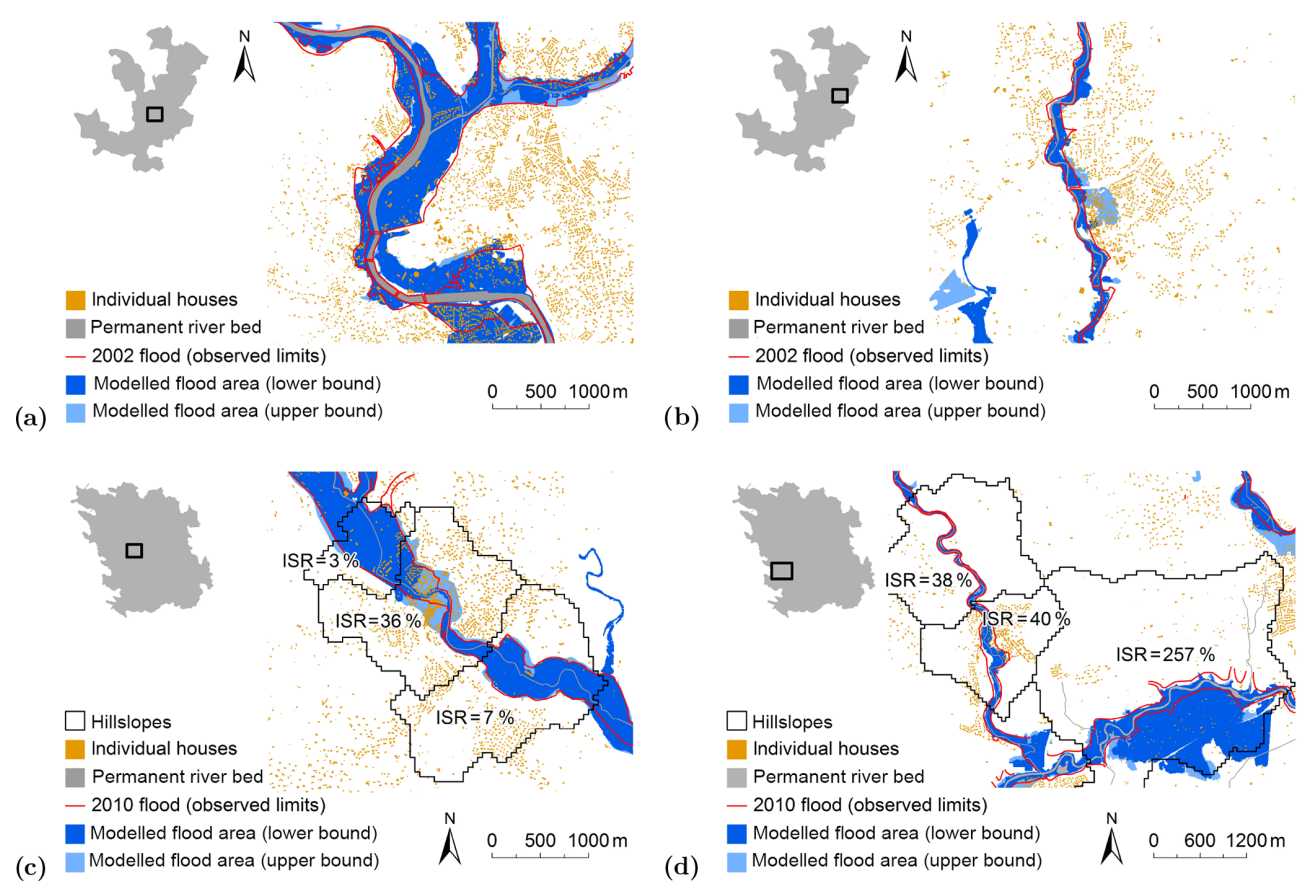

(b)

(d)

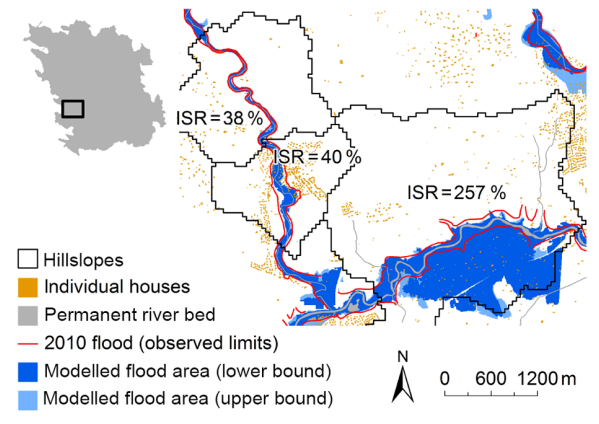

Figure 7. Examples of comparison between observed and estimated flood extents, and related ISR values (computed for the lower bounds of estimated flood extents): (a) Alès 2002 event for the Grabieux and Gardons rivers, (b) Alès 2002 event for the Avène river, (c) Draguignan 2010 event for the Nartuby river, and (d) Draguignan 2010 event for the Florieye and Argens rivers.

discharge relationship, even if this could not really be illustrated in the presented case study.

\subsection{Comparison with reference flooded areas (Alès case study)}

Reference flood maps have been produced for the purpose of the implementation of the EU Floods Directive for discharge values corresponding to the 30- and 300-year flood events for almost half of the considered stream reaches. The automatically computed maps could be compared to these reference maps for the same discharge values. For each river reach, the estimated surface (ES) and observed or reference surface (RS) are compared. The surface area in common $\left(S_{\mathrm{c}}\right)$, the excess surface area $\left(S_{\mathrm{e}}\right.$ : computed but not observed), and the default surface area $\left(S_{\mathrm{d}}\right.$ : observed but not computed $)$ are evaluated (Fig. 6a). Note that $\mathrm{ES}=S_{\mathrm{c}}+S_{\mathrm{e}}$ and $\mathrm{RS}=S_{\mathrm{c}}+S_{\mathrm{d}}$. A synthetic incoherent surface ratio (ISR) is then computed. It represents the extent of excess and default surfaces, expressed as a proportion of the reference surface (Eq. 1):

$\mathrm{ISR}=\frac{S_{\mathrm{e}}+S_{\mathrm{d}}}{\mathrm{RS}}$.

The permanent river bed (represented in Fig. 6a) which is not affected by estimation uncertainties, is not considered in the computation of the surfaces ES and RS and hence in the computation of ISR.

Figure $6 \mathrm{~b}$ presents the distributions of ISRs computed for the 84 river reaches for which reference inundation maps were available (71 reaches for the 30-year flood) for the Alès case study. The results appear overall satisfactory: the ISR rarely exceeds $30 \%$. This ratio includes both default and excess surfaces: the real difference between ES and RS is in fact more limited. This suggests that the errors in the estimation of impacts will also be more limited. The ISR is sensitive to small differences between computed and reference maps as illustrated by the examples shown in Fig. 7 and low values are difficult to reach and suggest a quasi perfect agreement. Figure $6 \mathrm{c}$ also shows that the ISR values depend on the magnitude of the simulated floods. The results obtained for the 300-year flood appear much more accurate, with ISRs almost never exceeding $50 \%$. This can be explained by the fact that the floodplains are largely flooded in the case of high return period discharges, with limited possibilities for large errors. The estimation of the flooded areas for the 30-year discharges appear less accurate, with a significant proportion of stream reaches with large relative errors: ISRs exceeding $100 \%$ for almost $10 \%$ of the reaches. These relative errors are nevertheless essentially related to observed flooded surfaces less than $0.1 \mathrm{~km}^{2}$ (Fig. 6c). This corresponds to the very beginning of the river overflow that is hardly captured accurately with a hydraulic model based on automatic extractions from a DTM, whose roughness parameters are averaged over large areas and with no description of local hydraulic singularities. However, large relative errors in small flooded areas will have limited influence on the impact model. Overall, the simulated flooded areas correspond pretty well to the refer- 


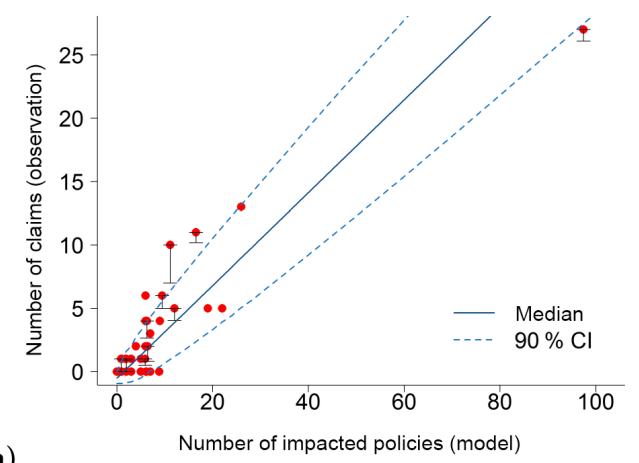

(a)

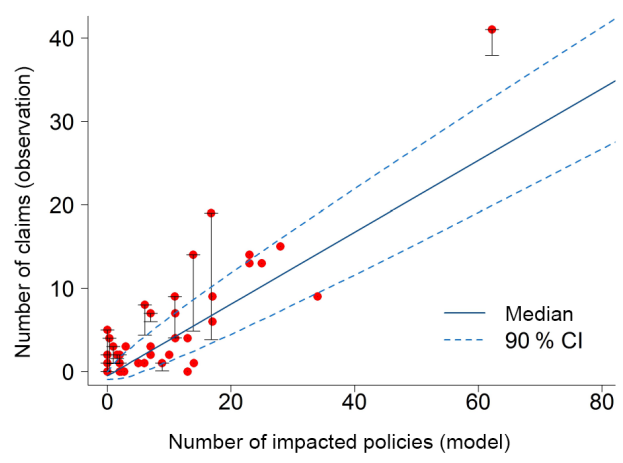

(b)

Figure 8. Comparison of estimated number policies affected by the flood (model), and associated number of claims for each river reach: (a) Alès 2002 event and (b) Draguignan 2010 event. Blue lines correspond to the mean claims / policies binomial relationship and associated $90 \%$ confidence interval, vertical bars represent uncertainty in the number of claims related to river flooding.

ence areas. These results confirm the validation results obtained from the rating curves: the proposed 1-D hydraulic model, based on automatic extractions from relatively accurate DTM and on a regionally averaged roughness coefficient, stands overall reasonably well compared with local expert-based hydraulic models, at least in the test region. Some reasons can be put forward to explain this result: the limited need of bathymetric data in the Mediterranean context; the river slopes - typically $0.5 \%$ or more - limiting the distance over which backwater effects propagate and therefore the local influence of hydraulic singularities not taken into account in the model; the reduced sensitivity of water stages $(h)$ to variations of discharges $(Q)$ due to the typical shape of stage-discharge relationships $\left(h \propto Q^{3 / 5}\right)$; finally, the reduced sensitivity of the flooded area to the water stages, except at the beginning of the river overflow, due to the crosssectional shapes of the river beds, with generally narrow valleys and well-delimited flat flood plains.

\subsection{Accuracy of forecasted flood extents for the Alès 2002 and Draguignan 2010 floods}

For both considered validation flood events, observed inundated areas were carefully mapped after the floods on part of the affected streams. These observed flood extent maps were compared for each river reach to the forecasted flood extents. More precisely, the ISRs described in the previous section were computed based on the map of the flood catalogue corresponding to a discharge value immediately lower or equal to the simulated peak discharge value. There is indeed not necessarily a map in the catalogue corresponding to the exact value of the simulated peak discharge. This choice should lead to a slight underestimation of the flooded areas if the hydrological and hydraulic models were perfect. This is illustrated in Fig. 7, which shows for some river reaches, the observed flood extent and both modelled extents corresponding to the discharge values immediately lower and higher than the forecasted peak discharge. This figure also shows to what range of differences the ISR values correspond.

The ISRs obtained for both events are summarised in Fig. 6d. Without surprise, the ISR values are significantly increased when actual flood events are considered, if compared to the initial evaluation of the catalogue of flooded areas presented in the previous section. When actual floods are simulated, additional sources of uncertainties affect the computed flooded areas. The simulated peak discharge on which the forecasted maps are based may differ significantly from the observed ones. Moreover, the observed flooded areas may be the result of local processes (dike breaches, blockages) particularly during extreme flood events. These processes are not represented in the hydraulic models, either the proposed simplified regional model or the local models used to elaborate the reference flood maps. In fact, Fig. 7 shows that the differences between observed and simulated flood extents are explained not only by uncertainties in the simulated peak discharge values which would result in systematic over or underestimations of flood extents but also by local processes imperfectly accounted for in the hydraulic models.

Finally, a large proportion of the relative ISRs remains less than $50 \%$. Consequently, the computed flood extent maps may be sufficiently realistic to provide an approximation of the local field consequences of floods and of their spatial distribution. This is verified in the next section. It is noteworthy that the ISRs are lower in the case of the Draguignan 2010 flood despite that the models (rainfall-runoff and hydraulic models) were extrapolated to this event and area without any further calibration. This can be explained by the higher accuracy of the DTM available in this area. In any case, it is a promising result that seems to reveal that uncertainties related to the extrapolation of the models may be of secondary importance compared to the other sources of uncertainties of the proposed approach. Nevertheless general conclusions cannot be drawn from one single example. 


\subsection{Validation of forecasted impacts based on insurance claims}

Even after a careful selection of the appropriate validation data, the observed claim / policy ratio is significantly less than 1 (Table 2 and Fig. 4), and varies between river reaches. As shown in Sect. 3.6, this is explained by claims with no compensation and/or non-declared claims, buildings with raised basements, inaccurate location of insured buildings, and also the imperfect filling of the claim database. Clearly, the number of reported claims per river reach has a random component due both to the claim triggering processes and to the limits of the claim database. To account for randomness in the validation process, the number of reported claims can for instance be considered as the result of a random binomial process $B(n, p)$, with $n$ being the number of policies in the considered flooded area and $p$ the probability that a corresponding claim with non-null compensation is observed. If $p$ is considered to be the same for all reaches and equal to the average claim / policy ratio for the selected sample of insurance policies, a confidence interval ( $90 \%$ binomial confidence interval herein) can be estimated for the number of claims corresponding to every computed number of impacted policies (policies located in the estimated flooded area). Ideally, the average claim / policy ratio should be estimated inside the actually observed flooded area. However, this information is clearly not available everywhere on the considered stream networks. By default, the claim / policy ratios have been computed here within the 1000-year flood extent (Table 2). The result is presented in Fig. 8 for the two case studies.

This figure shows a relatively good agreement between the forecasted number of impacted policies and the number of reported claims per river reach. The observed spread of the results nevertheless exceeds the width of the $90 \%$ intervals, especially in the Draguignan 2010 case study: more than $10 \%$ of the dots lie outside the confidence limits with predominantly underestimations by the model. This indicates that some other sources of errors affect the relationship between forecasted and observed number of claims. First, the reported claim / policy ratio is significantly affected by water depth and flood duration, two variables that have not been considered here. Second, the claim / policy ratio and the reference number of claims have been computed based on the maximum possible estimated flood envelop (1000-year flood envelop), i.e. without using the observed flooded area (not available for a large part of the stream network), or the computed flooded area (which has to be evaluated and should therefore not be used in the validation process). This may lead to slight underestimation of the claim / policy ratio since some non-flooded areas are incorporated in the estimation. This choice may also lead to overestimating the reference claim number for stream reaches where limited overflow occurs, especially in densely urbanised areas (see points A and $\mathrm{B}$ in Fig. 8b), since a significant proportion of claims are not related to the streams represented in the model (Sect. 3.6). The number of reported claims in the computed flooded areas has also been estimated and the difference with the reference number of claims is indicated by the dotted lines in Fig. 8 . This difference is modest in the Alès 2002 case, where the floods have been extreme over the entire considered area. The correction is much more significant in the Draguignan case, especially for almost all the points located over the $95 \%$ confidence limit (Fig. 8b). Several of these reaches, particularly points A and B, are located in the upper south-eastern part of the studied area, which has not been affected by the most intense rainfalls. The observed flood extent was only partially mapped in this area after the 2010 flood, but the mapped extent indicates moderate overflow in this sector and is in good agreement with the modelled flooded area. The high number of claims located outside areas flooded by the streams modelled, the impossibility to separate these claims, and the absence of observed flood extent maps for stream affected by moderate floods clearly limit the use of the insurance claim database for the validation of flood impact models.

Finally, Fig. 9 compares the spatial distributions of the simulated peak discharges, of the maximum forecasted impacts (i.e. number of flooded private houses with georeferenced policy), and of the number of associated claims according to the CCR database. It should be noted that information on claims is provided only for river reaches with at least 20 policies recorded in the database. This explains why no values have been provided for several stream reaches, essentially non-urbanised reaches with limited exposed assets. This figure illustrates the large differences in the outputs of the hydrological rainfall-runoff model (Fig. 9a and b), and of the integrated rainfall-runoff-impact modelling chain (Fig. 9c and d) which provides a much contrasted analysis. It also shows good overall consistency between the forecasted impacts (Fig. 9c and d) and observed claims (Fig. 9e and $f$ ) for the location of the main hotspots. Apart from some exceptions, the ranking and magnitudes of the field impacts appears to be well captured by the proposed forecasting chain. That is mainly the information needed by rescue services to adapt and dispatch their rescue means during flood event management. Such information could also help targeting more effectively alert messages.

\section{Conclusions}

Flood event managers need to assess, in real time, the severity of possible field consequences associated with hydrometeorological forecasts, to be able to take appropriate decisions. Automatic assessment methods are necessary in the case of fast-evolving events such as flash floods, when little time is available for information processing and analysis. Moreover, the direct estimation of field consequences opens the possibility of testing the performance of forecast- 


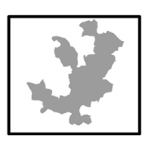

(a)
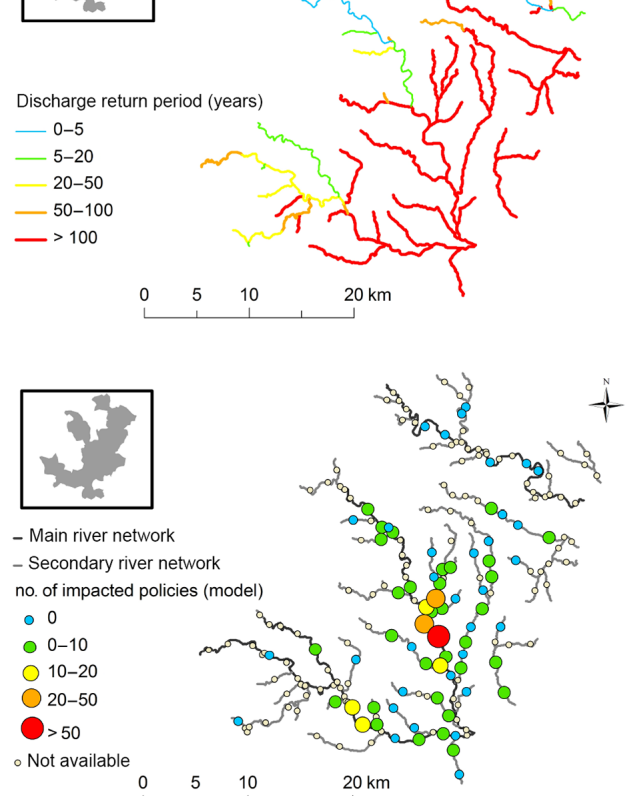

(c)

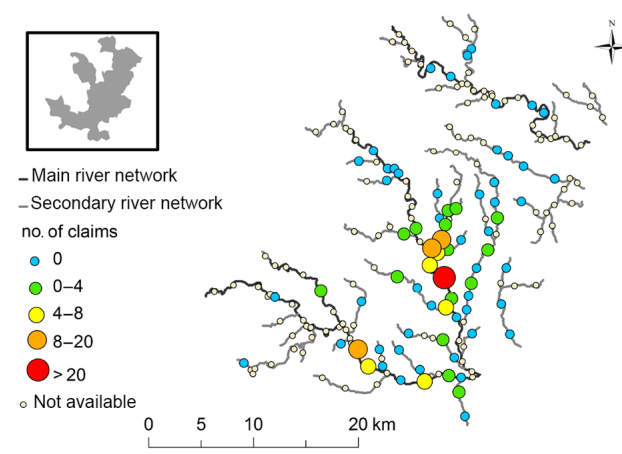

(e)

(d)

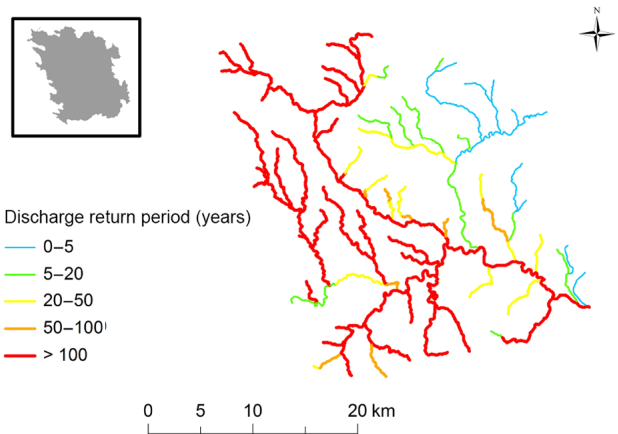

(b)

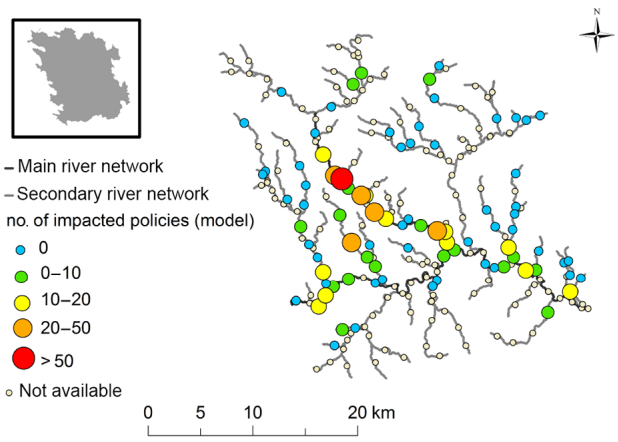

(f)

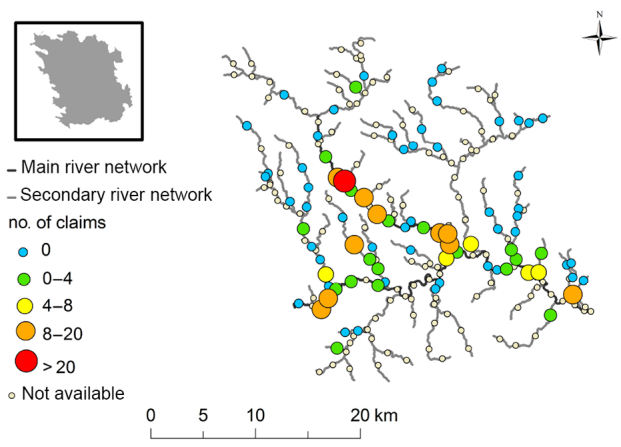

Figure 9. Maps of the peak discharges (return periods) and related impacts (number of flooded policies) simulated by the model, and of the number of claims extracted from the CCR database: (a) peak discharges, Alès 2002; (b) peak discharges, Draguignan 2010; (c) estimated impacts, Alès 2002; (d) estimated impacts, Draguignan 2010; (e) claims, Alès 2002; (f) claims, Draguignan 2010.

ing chains in ungauged areas, where various observations related to damages may be available.

This paper has tested the potential of simple approaches for the estimation of the magnitudes of possible field consequences within flash-flood forecasting chains. The proposed methods have been selected to be implemented with limited calibration effort, over extended areas, and at detailed spatial scales. Particular attention has been paid to the performance evaluation of the proposed chain. An original and particularly rich and comprehensive insurance claim database has therefore been used. It is to our knowledge the first time an insurance claim database is used for such a purpose.

The proposed approaches certainly deserve further validation, but the results presented herein on two case studies appear extremely satisfactory and promising. The flood map- ping based on 1-D steady-state hydraulic modelling, automatically implemented over a large river network with an average roughness value, stands the comparison, for most of the considered river reaches, with local expert-based hydraulic simulations: stage-discharge relationships at gauging stations and flood maps computed for the implementation of the EU Floods Directive. The whole hydrological and hydraulic simulation chain provides estimates of maximum flooded areas that also appear generally close to the flood extents mapped after the two test events when such maps were available. The typical configuration of the streams affected by flash floods can be put forward to explain such satisfactory results: (i) narrow valleys and welldelimited floodplains, (ii) limited need for bathymetric data for Mediterranean streams, (iii) steep stream slopes implying 
limited spatial influence of hydraulic singularities (bridges) and their induced backwater effects, and (iv) huge discharge contrasts between moderate, large, and extreme floods that are well captured by rainfall-runoff models despite the inevitable modelling uncertainties. The slightly better results obtained in the Draguignan case suggest that some improvements could still be achieved with more accurate topographic data, especially lidar data enabling better retrieval of the cross-sectional shape of the main stream bed. The influence of the DTM accuracy on the results of the proposed approach will have to be tested. Some other difficulties nevertheless remain. The proposed modelling approach has to be further improved to properly handle complex hydraulic configurations such as perched river beds (Fig. 5). And the observed flood extents may also locally differ from the estimated flooded area even if the discharge value has been well forecasted due to local effects difficult to anticipate such as blockages and breaches. A perfect fit is out of reach. This suggests that we should not put too much confidence in theoretical flood maps computed either a priori or in real time. Such maps, if provided to the flood event managers, should be presented as indications of possible flood scenarios close but not identical to the actual flood.

The validation of the estimated damages based on insurance claims faced some difficulties related to the specificity of insurance data. The CCR database used is probably the most comprehensive source of information about flood insurance losses in France. However, the validation process requires both accurate geocoding of insurance policies and comprehensive information on claims, which limits the amount of available information. A high proportion of claims is also not related to the streams included in the model, limiting the possibility of using this data as a reference for moderate floods if the actual flood extent is unknown (Fig. 8). The validation exercise could nevertheless be successfully achieved for the two extreme floods studied herein, providing interesting additional information on the accuracy of the whole simulation chain. It should also be considered that the quality of insurance data is continuously increasing and that some of the limits identified here (e.g. geocoding, comprehensiveness of claim information) should be significantly reduced in the future. Moreover, better representation of the claims triggering processes should be possible based on the inundation water depths obtained from the hydraulic computations; direct relationships between the claim ratios and water depths are indeed commonly used by insurance companies. Therefore, insurance claim data should be considered a relevant option for the validation of flood forecasting results, particularly in the case of flash floods affecting ungauged rivers. Although data of this sort are generally confidential, they may be accessible through partnerships with insurance companies. Other sources of information on flash flood impacts could also be used, such as the $\operatorname{logs}$ of emergency services, emergency calls, information shared on social networks (USDHS, 2012; Jongman et al.,
2015; Tkachenko et al., 2017), or information gathered in the field after or during the event (Ortega et al., 2009; Ruin et al., 2014). This information is also affected by uncertainties and severe biases, especially in flash flood situations: absence of information due to local breakdowns of communication networks, reduction of social network activity, and partial filling of emergency logs in strongly affected areas during the turmoil of the event. Some of this information has nevertheless the benefit of being available in real time (digitised logs, emergency calls, social networks) and could help validate and improve forecasted impacts. Finally, the combined use of flood impact forecasting models and field data mining and processing methods is without doubts a promising avenue for the development of innovative flood forecasting and warning services.

Data availability. Most of the data used in this study are not under open licence and cannot be provided for direct download. The main data providers were:

- the Institut Géographique National (IGN; http://www.ign.fr) and the Conseil Départemental du Gard (http://www.gard.fr) for DTM data.

- the Direction Régionale de l'Environnement, de l'Aménagement et du Logement Auvergne Rhone Alpes, Service de Prévision des Crues du Grand Delta (DREAL Auvergne Rhone Alpes, SPC Grand Delta; http: //www.auvergne-rhone-alpes.developpement-durable.gouv.fr) for stream gauge data and rating curves.

- the OHM-CV observatory (http://www.ohmcv.fr) and Hymex program (http://www.hymex.org) for QPEs. The radar and rain gauge input data were provided by Météo-France, the SPC Grand Delta, and Electricité de France (EDF).

- the CCR for insurance claim data (www.ccr.fr).

Competing interests. The authors declare that they have no conflict of interest.

Acknowledgements. The authors would like to express their gratitude to François Bourgin for his careful reading of the manuscript. They also want to thank the following:

- The French Ministry of Environment, Direction Générale de la Prévention des Risques, Service Central D’Hydrométéorologie et d'Appui à la Prévision des Inondations (DGPR/SCHAPI, http://vigicrues.gouv.fr), for the financial support of this work.

- The DREAL Auvergne Rhone Alpes, SPC Grand Delta, the Conseil Départemental du Gard, and the IGN, for supplying part of the data.

- The OHM-CV observatory and the HyMeX program for their help in accessing the rainfall data (QPEs). OHM-CV is an observation service supported by the Institut National des Sciences de l'Univers, section Surface et Interfaces Continentales and the Observatoire des Sciences de l'Univers de Grenoble. $\mathrm{OHM}-\mathrm{CV}$ is a key observation system of the HyMeX program. 
Edited by: Matjaz Mikos

Reviewed by: three anonymous referees

\section{References}

Aubert, Y., Arnaud, P., Ribstein, P., and Fine, J.-A.: La méthode SHYREG - application sur 1605 bassins versants en France métropolitaine, Hydrolog. Sci. J., 59, 993-1005, https://doi.org/10.1080/02626667.2014.902061, 2014.

Borah, D., Prasad, S., and Alonso, C.: Kinematic wave routing incorporating shok fitting, Water Resour. Res., 3, 529-541, 1980.

Bradbrook, K., Waller, S., and Morris, D.: National Floodplain Mapping: Datasets and Methods $-160.000 \mathrm{~km}$ in 12 months, Natural Hazards, 36, 103-123, https://doi.org/10.1007/s11069004-4544-9, 2005.

Cole, J., Moore, R., Wells, S., and Mattingley, P.: Realtime forecasts of flood hazard and impact: some UK experiences, E3S Web of Conferences, p. 18015, https://doi.org/10.1051/e3sconf/20160718015, 2016.

Cole, S. J. and Moore, R. J.: Distributed hydrological modelling using weather radar in gauged and ungauged basins, Adv. Water Resour., 32, 1107-1120, https://doi.org/10.1016/j.advwatres.2009.01.006, 2009.

Delrieu, G., Nicol, J., Yates, E., Kirstetter, P.-E., Creutin, J.-D., Anquetin, S., Obled, C., Saulnier, G.-M., Ducrocq, V., Gaume, E., Payrastre, O., Andrieu, H., Ayral, P.-A., Bouvier, C., Neppel, L., Livet, M., Lang, M., du Chatelet, J. P., Walpersdorf, A., and Wobrock, W.: The Catastrophic Flash-Flood Event of 8-9 September 2002 in the Gard Region, France: A First Case Study for the Cévennes-Vivarais Mediterranean Hydrometeorological Observatory, J. Hydrometeorol., 6, 34-52, 2005.

Delrieu, G., Boudevillain, B., Nicol, J., Chapon, B., Kirstetter, P.E., Andrieu, H., and Faure, D.: Bollène - 2002 Experiment: Radar Quantitative Precipitation Estimation in the CévennesVivarais Region, France, J. Appl. Meteorol. Clim., 48, 14221447, https://doi.org/10.1175/2008JAMC1987.1, 2009.

Gaume, E., Livet, M., Desbordes, M., and Villeneuve, J. P.: Hydrologic analysis of the Aude, France, flash flood 12 and 13 november 1999, J. Hydrol., 286, 135-154, https://doi.org/10.1016/j.jhydrol.2003.09.015, 2004.

Gaume, E., Bain, V., Bernardara, P., Newinger, O., Barbuc, M., Bateman, A., Blaškovičová, L., Blöschl, G., Borga, M., Dumitrescu, A., Daliakopoulos, I., Garcia, J., Irimescu, A., Kohnova, S., Koutroulis, A., Marchi, L., Matreata, S., Medina, V., Preciso, E., Sempere-Torres, D., Stancalie, G., Szolgay, J., Tsanis, I., Velasco, D., and Viglione, A.: A compilation of data on European flash floods, J. Hydrol., 367, 70-78, https://doi.org/10.1016/j.jhydrol.2008.12.028, 2009.

Georgakakos, K. P.: Analytical results for operational flash flood guidance, J. Hydrol., 317, 81-103, https://doi.org/10.1016/j.jhydrol.2005.05.009, 2006.

Gourley, J., Flamig, Z., Vergara, H., Kirstetter, P.-E., Clark, R., Argyle, E., Arthur, A., Martinaitis, S., Terti, G., Erlingis, J., Hong, Y., and Howard, K.: The Flash project: improving the tools for flash flood monitoring and prediction across the United States, B. Am. Meteorol. Soc., 98, 361-372, 2017.

Gourley, J. J., Flamig, Z. L., Hong, Y., and Howard, K. W.: Evaluation of past, present and future tools for radar-based flash- flood prediction in the USA, Hydrolog. Sci. J., 59, 1377-1389, https://doi.org/10.1080/02626667.2014.919391, 2014.

Goutal, N., Lacombe, J.-M., Zaoui, F., and El-Kadi-Abderrezzak, K.: MASCARET: A 1-D open-source software for flow hydrodynamic and water quality in open channel networks, in: River Flow 2012 vols 1 and 2, edited by: Munoz, R., 1169-1174, CRC Press - Tailor and Francis Group, Boca Raton, USA, 2012.

Javelle, P., Demargne, J., Defrance, D., Pansu, J., and Arnaud, P.: Evaluating flash-flood warnings at ungauged locations using post-event surveys: a case study with the AIGA warning system, Hydrolog. Sci. J., 59, 1390-1402, https://doi.org/10.1080/02626667.2014.923970, 2014.

Jongman, B., Wagemaker, J., Romero, B., and de Perez, E.: Early Flood Detection for Rapid Humanitarian Response: Harnessing Near Real-Time Satellite and Twitter Signals, ISPRS Int. J. GeoInf., 4, 2246-2266, https://doi.org/10.3390/ijgi4042246, 2015.

Le Bihan, G., Payrastre, O., Gaume, E., Moncoulon, D., and Pons, F.: Regional models for distributed flashflood nowcasting: towards an estimation of potential impacts and damages, E3S Web of Conferences, p. 18013, https://doi.org/10.1051/e3sconf/20160718013, 2016.

Lumbroso, D. and Gaume, E.: Reducing the uncertainty in indirect estimates of extreme flash flood discharges, J. Hydrol., 414-415, 16-30, https://doi.org/10.1016/j.jhydrol.2011.08.048, 2012.

Moncoulon, D., Labat, D., Ardon, J., Leblois, E., Onfroy, T., Poulard, C., Aji, S., Rémy, A., and Quantin, A.: Analysis of the French insurance market exposure to floods: a stochastic model combining river overflow and surface runoff, Nat. Hazards Earth Syst. Sci., 14, 2469-2485, https://doi.org/10.5194/nhess14-2469-2014, 2014.

Moussa, R.: Analytical Hayami solution for the diffusive wave flood routing problem with lateral inflow, Hydrol. Process., 10, 12091227, 1996.

Naulin, J.-P., Payrastre, O., and Gaume, E.: Spatially distributed flood forecasting in flash flood prone areas: Application to road network supervision in Southern France, J. Hydrol., 486, 88-99, https://doi.org/10.1016/j.jhydrol.2013.01.044, 2013.

Nguyen, P., Thorstensen, A., Sorooshian, S., Hsu, K., and AghaKouchak, A.: Flood Forecasting and Inundation Mapping Using HiResFlood-UCI and Near-Real-Time Satellite Precipitation Data: The 2008 Iowa Flood, J. Hydrometeorol., 16, 1171-1183, https://doi.org/10.1175/JHM-D-14-0212.1, 2015.

Norbiato, D., Borga, M., Esposti, S. D., Gaume, E., and Anquetin, S.: Flash flood warning based on rainfall thresholds and soil moisture conditions: An assessment for gauged and ungauged basins, J. Hydrol., 362, 274-290, https://doi.org/10.1016/j.jhydrol.2008.08.023, 2008.

Ortega, K., Smith, T., Manross, K., Scharfenberg, K., Witt, A., Kolodziej, A., and Gourley, J.: The severe hazards analysis and verification experiment, B. Am. Meteorol. Soc., 90, 1519-1530, https://doi.org/10.1175/2009BAMS2815.1, 2009.

Pappenberger, F., Dutra, E., Wetterhall, F., and Cloke, H. L.: Deriving global flood hazard maps of fluvial floods through a physical model cascade, Hydrol. Earth Syst. Sci., 16, 4143-4156, https://doi.org/10.5194/hess-16-4143-2012, 2012.

Pons, F., Laroche, C., Fourmigue, P., and Alquier, M.: Cartographie des surfaces inondables extrêmes pour la directive inondation: cas de la Nartuby, La Houille Blanche, 2, 34-41, https://doi.org/10.1051/lhb/2014014, 2014. 
Rozalis, S., Morin, E., Yair, Y., and Price, C.: Flash flood prediction using an uncalibrated hydrological model and radar rainfall data in a Mediterranean watershed under changing hydrological conditions, J. Hydrol., 394, 245-255, https://doi.org/10.1016/j.jhydrol.2010.03.021, 2010.

Ruin, I., Lutoff, C., Boudevillain, B., Creutin, J., Anquetin, S., Rojo, M., Boissier, L., Bonnifait, L., Borga, M., Colbeau-Justin, L., Creton-Cazanave, L., Delrieu, G., Douvinet, J., Gaume, E., Gruntfest, E., Naulin, J., Payrastre, O., and Vannier, O.: Social and hydrological hesponses to extreme precipitations: an interdisciplinary strategy for postflood investigation, Weather and Climate Society, 6, 135-153, 2014.

Saint-Martin, C., Fouchier, C., Javelle, P., Douvinent, J., and Vinet, F.: Assessing the exposure to floods to estimate the risk of flood-related damage in French Mediterranean basins, E3S Web of Conferences, p. 04013, https://doi.org/10.1051/e3sconf/20160704013, 2016.

Sampson, C., Smith, A., Bates, P., Neal, J., Alfieri, L., and Freer, J.: A high-resolution global flood hazard model, Water Resour. Res., 51, 7358, https://doi.org/10.1002/2015WR016954, 2015.

Sanders, B. F.: Evaluation of on-line \{DEMs\} for flood inundation modeling, Adv. Water Resour., 30, 1831-1843, https://doi.org/10.1016/j.advwatres.2007.02.005, 2007.

Schroeder, A., Gourley, J., Henderson, J., Parhi, P., Rahmani, V., Reed, K., Schumacher, R., B.K., S., and Taraldsen, M.: The development of a flash flood severity index, J. Hydrol., 541, 523532, https://doi.org/10.1016/j.jhydrol.2016.04.005, 2016.

Tkachenko, N., Jarvis, S., and Procter, R.: Predicting floods with Flickr tags, PLoS One, 12, e0172870, https://doi.org/10.1371/journal.pone.0172870, 2017.

USDA: Urban hydrology for small watersheds, Technical Release N. 55, Tech. rep., United States Department of Agriculture, Natural Resources Conservation Service, Washington DC, 1986.
USDHS: First responder communities of practice, virtual social media working group, community engagement guidance and best practice, Tech. rep., United States Department of Homeland Security, Science and technology directorate, Washington DC, 2012.

Versini, P.-A., Gaume, E., and Andrieu, H.: Application of a distributed hydrological model to the design of a road inundation warning system for flash flood prone areas, Nat. Hazards Earth Syst. Sci., 10, 805-817, https://doi.org/10.5194/nhess-10-8052010, 2010a.

Versini, P.-A., Gaume, E., and Andrieu, H.: Assessment of the susceptibility of roads to flooding based on geographical information - test in a flash flood prone area (the Gard region, France), Nat. Hazards Earth Syst. Sci., 10, 793-803, https://doi.org/10.5194/nhess-10-793-2010, 2010b.

Versini, P.-A., Berenguer, M., Corral, C., and Sempere-Torres, D.: An operational flood warning system for poorly gauged basins: demonstration in the Guadalhorce basin (Spain), Natural Hazards, 71, 1355-1378, https://doi.org/10.1007/s11069-013-09497, 2014.

Wang, J., Yang, H., Li, L., Gourley, J., Khan, S., Yilmaz, K., Adler, R., Policelli, F., Habib, S., Irwn, D., Limaye, A., Korme, T., and Okello, L.: The coupled routing and excess storage (CREST) distributed hydrological model, Hydrolog. Sci. J., 56, 84-98, https://doi.org/10.1080/02626667.2010.543087, 2011.

Yamazaki, D., Kanae, S., Kim, H., and Oki, T.: A physically based description of floodplain inundation dynamics in a global river routing model, Water Resour. Res., 47, w04501, https://doi.org/10.1029/2010WR009726, 2011. 